verossimilhança exigidos por lei, além do que, o risco para a reclamante mostra-se patente, mormente porque se trata de garantia da integridade física da mesma e de seus dependentes, além de o dano irreparável ligar-se à situação de insegurança quanto à qualidade do tratamento médico-hospitalar necessário para resgatar uma vida saudável, e portanto, mais digna”. Com efeito, preenchidos os pressupostos exigidos pelo art. 273 do CPC, sobretudo, mais do que a verossimilhança, a certeza da alegação e o fundado receio de dano irreparável ou de difícil reparação, visando assegurar o resultado útil do processo (art. 461, CPC), agiu acertadamente o juízo de origem em conceder a tutela antecipada na forma postulada pela autora. Nego provimento.

\title{
CONCLUSÃO
}

Rejeito a preliminar de deserção argüida e conheço do recurso. No mérito, nego-lhe provimento. Fundamentos pelos quais, o Tribunal Regional do Trabalho da Terceira Região, pela sua Turma Recursal de Juiz de Fora, julgou o presente processo e, à unanimidade, conheceu do recurso; sem divergência, rejeitou a preliminar de deserção argüida e, no mérito, negouIhe provimento. Juiz de Fora, 11 de março de 2008. Des. José Miguel de Campos, Presidente e Relator.

PROCESSO : 00731-2007-035-03-00-7 RO

\section{Direito Sanitário e Relações de Trabalho}

\author{
HEALTH LAWAND WORK
}

Alexandre Barenco Ribeiro ${ }^{(*)}$

O Direito Sanitário apresenta como uma de suas principais características a interação harmônica com os diversos ramos do Direito. O professor

(*) Especialista em Direito do Trabalho pela Pontifícia Universidade Católica do Rio de Janeiro (PUC-RJ), mestre em Direito pela Faculdade de Direito de Campos, professor convidado integrante do Núcleo de Direito e Saúde, da Fundação Oswaldo Cruz, professor de Direito Constitucional da Escola de Magistratura do Estado do Rio de Janeiro, professor de Direito do Programa de Pós-Graduação da PUC-RJ. $<$-E-mail: alexandrebarenco @ barencopinheiro.adv.br>. Recebido em 15.9.08. Aprovado em 2.10.08. 
Paulo Condocert(1) lecionava em suas aulas de Introdução à Ciência do Direito na Faculdade Nacional de Direito, da Universidade Federal do Rio de Janeiro, que o Direito é um sistema integrado, funcionando como uma bolsa, na qual tudo que se precisa para o ordenamento das relações sociais está dentro, resta apenas saber em que compartimento da bolsa está escondido.

O Direito Sanitário é um novo ramo do Direito que trata de questões antigas inseridas na sociedade desde que ela foi constituída. Passa o Direito Sanitário a apresentar soluções para demandas relacionadas à saúde pública, entendida aqui da forma mais ampla possível que, até então, eram resolvidas por outros ramos do Direito como, por exemplo, o Direito Constitucional, o Direito Administrativo, o Direito do Trabalho, o Direito Previdenciário, o Direito Penal, o Direito Civil, o Direito Ambiental e o Direito do Consumidor.

Sendo o Direito Sanitário o conjunto de regras e princípios que visam diminuir, restringir e eliminar os riscos à saúde, funciona como um importante catalisador dos diferentes ramos do Direito para a solução integrada e equânime das demandas específicas que Ihe são apresentadas e, assim, evitando o aparecimento de decisões contraditórias.

Infelizmente, são poucas as instituições de ensino superior no campo de Direito que disponibilizam o Direito Sanitário como disciplina curricular. A resultante é uma carência informativa dos operadores do Direito e a aplicação dos institutos e princípios informativos do Direito Sanitário, muitas vezes, de forma inconsciente.

No caso sob análise, a assertiva articulada acima fica evidente. A decisão judicial ora comentada foi prolatada pelo Tribunal Regional do Trabalho da $3^{a}$ Região - Minas Gerais - tendo por objeto a possibilidade ou não de manutenção de assistência médica disponibilizada pelo empregador aos seus empregados, quando um dos trabalhadores acaba sendo aposentado por invalidez.

Mesmo sem ter tal consciência, não só o julgador de primeiro grau, mas também o Colegiado ad quem, operaram regras de Direito Sanitário para solucionar uma demanda que, até pouco tempo atrás, era apreciada sob a ótica exclusiva dos Direitos do Trabalho e Previdenciário.

A Constituição Federal estabelece a partir do seu art. 201, as regras gerais para a obtenção da aposentadoria por meio do Regime Geral de Previdência. Esta matéria foi regulamentada em nível infraconstitucional em 1991, pelas Leis Federais n. 8.212 e 8.213.

Coube também ao atual Texto Constitucional normatizar o sistema de previdência dos servidores públicos efetivos, tarefa que foi realizada mediante do seu art. 40, ficando a cargo de cada ente federativo (União, Estados,

(1) O professor Paulo Condorcet lecionou a matéria Introdução à Ciência do Direito na Faculdade Nacional de Direito - FND. 
Distrito Federal e Municípios) a regulamentação da questão por meio dos seus Estatutos de Servidores Públicos.

Considerando que o objeto desta análise é a decisão prolatada pelo Tribunal Regional do Trabalho de Minas Gerais, versando sobre problemas decorrentes de vínculo de emprego entre uma trabalhadora e um empregador, não serão debatidas as questões pertinentes ao regime especial de previdência, destinado aos servidores públicos efetivos ${ }^{(2)}$.

O ordenamento constitucional reconhece a possibilidade de duas modalidades de aposentadoria: a voluntária e a compulsória. No caso da aposentadoria voluntária, o trabalhador preenche os requisitos mínimos de tempo de contribuição estabelecidos pela legislação (trinta e cinco anos para homens e trinta anos para as mulheres); ou atinge a idade de sessenta e cinco anos de idade para os homens e sessenta anos de idade para as mulheres. Em ambos os casos, o interessado formula seu pedido e, presentes os requisitos destacados, a aposentadoria será concedida. Trata-se de um ato administrativo vinculado.

Já nas hipóteses de aposentadoria compulsória, o trabalhador não tem nenhuma governabilidade sobre a concessão do benefício; estando presentes as condições legais para a concessão do benefício previdenciário, ele será implantado mesmo que não seja esta a vontade do trabalhador. Em outras palavras, presentes os requisitos legais, o trabalhador é aposentado independentemente de sua iniciativa neste sentido.

No caso das aposentadorias por invalidez, o Instituto Nacional de Seguro Social (INSS), autarquia federal responsável pela tutela das questões relacionadas à previdência e à assistência social, tem a atribuição de analisar as condições de saúde do segurado, verificando se existe a possibilidade de manutenção de seu vínculo empregatício ou não.

$\mathrm{Na}$ verdade, a autarquia federal avalia a capacidade laborativa do trabalhador, diante da nova limitação imposta pelo acidente sofrido ou pela doença contraída. Também compete ao INSS a análise da hipótese de readaptação do empregado-segurado.

Havendo condições para a manutenção das atividades do segurado, o INSS disponibilizará os cursos necessários para a adaptação do trabalhador as suas novas limitações físicas ou psicológicas, sendo, nesses casos, afastada a aposentadoria por invalidez.

Muitas vezes de forma equivocada, a autarquia federal investe na manutenção da capacidade laborativa do empregado. Tal situação tem gerado algumas demandas judiciais e conflitos na área da saúde, pois, não são

(2) Apenas para uniformizar os conceitos, servidores públicos efetivos são aqueles vinculados ao regime legal e aprovados previamente em concurso público de prova ou de prova e títulos para o preenchimento do cargo público. 
raros os casos onde o médico, perito do INSS, atesta a aptidão para o trabaIho do empregado, enquanto outro médico (também do setor público) atesta a incapacidade laborativa do empregado, indicando a sua aposentadoria por invalidez.

O que fazer nestes casos? A pergunta ficará no ar, pois seria tema para outro comentário.

De qualquer sorte, superadas as divergências médicas, estando o empregado incapacitado para o desempenho de suas atividades laborativas e não havendo possibilidade de readaptação em outra função, o trabaIhador será aposentado, mesmo que essa não seja a sua vontade.

A intenção neste caso é preservar a vida e a dignidade do trabalhador que, certamente, teria o seu estado de saúde prejudicado pela continuidade do trabalho com as novas limitações físicas ou psicológicas.

Vale esclarecer que a aposentadoria por invalidez é remunerada, em regra, com proventos proporcionais ao tempo de contribuição, o que não é compreendido por todos, uma vez que o senso comum construiu a ideia da aposentadoria por invalidez remunerada com proventos integrais; ou seja, remunerada com os mesmos valores recebidos pelo trabalhador quando em atividade.

$\mathrm{Na}$ verdade, a aposentadoria por invalidez com proventos integrais é exceção. Ela se materializará nos casos em que o fato limitador da capacidade laboral do segurado tem sua origem na atividade profissional do segurado.

Existe ainda uma relação de doenças que acarretam na decretação da aposentadoria por invalidez e, também nesses casos, os proventos percebidos pelo aposentado serão integrais, independentemente do tempo de contribuição e da doença ter sido contraída em decorrência da atividade laboral.

Atualmente, está pacificado na doutrina, e também na jurisprudência, que a aposentadoria por invalidez não é definitiva. Considerando o fato gerador da aposentadoria por invalidez e contando ainda com a constante evolução tecnológica da medicina, é possível que a limitação física ou psicológica da capacidade laborativa do segurado, que motivou a decretação da aposentadoria compulsória do trabalhador, seja revertida no futuro por meio da cura da anomalia.

A explicação para a reversibilidade da aposentadoria compulsória por invalidez é bem lógica: havendo o restabelecimento da capacidade laborativa do trabalhador aposentado, não existe mais razão para a manutenção da inatividade remunerada.

Destarte, a aposentadoria por invalidez acaba sendo uma modalidade de aposentadoria compulsória considerada reversível e, portanto, não apresenta caráter definitivo, ao contrário do que acontece com a aposentadoria compulsória em razão da idade. 
Dentro deste contexto, o Direito do Trabalho trata da aposentadoria por invalidez como sendo uma das hipóteses de suspensão do contrato de trabalho, na forma do entendimento pretoriano consolidado por meio do Enunciado da Súmula n. 160, do Tribunal Superior do Trabalho(3).

Toda relação de emprego decorre de um contrato de trabalho, que pode ser expresso ou tácito, e tem as suas regras cogentes estabelecidas pela Constituição Federal e pela Consolidação das Leis do Trabalho (CLT), sem prejuízo das demais normas específicas.

A Consolidação das Leis do Trabalho é responsável por ordenar, em nível infraconstitucional, as relações de trabalho. Tal diploma legal reza sobre a interrupção e a suspensão do contrato de trabalho em seus arts. 471 a 476, cabendo à doutrina apresentar a diferenciação entre esses dois institutos.

Como traço comum entre a suspensão e a interrupção do contrato de trabalho, pode-se salientar o fato de que, tanto na interrupção, como na suspensão do contrato de trabalho, tem-se a paralisação temporária da prestação de serviço decorrente do contrato de trabalho.

Fundamental compreender, no entanto, que durante a interrupção e a suspensão do contrato de trabalho, este continua em vigor, não havendo a sua rescisão e, portanto, sendo mantido o vínculo laboral e a maioria das suas condições, existindo deveres e obrigações para todas as partes contratantes. Quando o contrato de trabalho está interrompido ou suspenso, o empregado ainda é empregado e o empregador continua sendo empregador; no entanto, existem limitações no exercício dos direitos potestativos pertencentes ao empregador.

A doutrina assevera que o empregador não pode, durante a interrupção ou a suspensão do contrato de trabalho, rescindi-lo, ainda que se disponha a arcar com todos os custos inerentes à rescisão imotivada do vínculo empregatício.

Nesta hipótese, a polêmica reside na aplicação da rescisão contratual punitiva, também chamada de dispensa por justa causa, se presente uma das hipótese expressas do art. 182 da CLT. No entanto, mesmo diante das familiaridades existentes, a interrupção e a suspensão do contrato de trabaIho não se confundem.

Na interrupção, o empregador é responsável pelo pagamento de salário e existe a contagem de tempo de serviço para fins de aposentadoria e demais efeitos legais.

(3) Enunciado da Súmula n. 160 do TST — Cancelada a aposentadoria por invalidez, mesmo após 5 anos, o trabalhador terá direito de retornar ao emprego, facultado, porém, ao empregador indenizá-lo na forma da lei. 
Já na suspensão do contrato de trabalho não existe o pagamento de salários por parte do empregador, nem o tempo de afastamento é considerado para efeitos legais.

Considerando as circunstâncias que cercam a aposentadoria por invalidez, ela é capitulada pela doutrina e pela jurisprudência como sendo uma hipótese de suspensão do contrato de trabalho.

Assim, o trabalhador aposentado por invalidez continua com seu contrato de trabalho vigente e todas as suas cláusulas aplicáveis (ou pelo menos a maioria delas). Também está assegurada a incidência das regras de proteção ao trabalhador estabelecidas pela CLT dentre as quais está a consignada no art. 468 do Texto Consolidado, que proíbe a alteração unilateral do contrato de trabalho por iniciativa do empregador, quando tal modificação trouxer prejuízos diretos ou indiretos ao empregado.

A decisão judicial prolatada pelo Tribunal Regional do Trabalho da Terceira Região, que enseja a análise em tela, deixa evidenciado que a empregada recorrida preservou a condição de empregada mesmo com a concessão da aposentadoria por invalidez. O Tribunal mineiro acolhe o entendimento predominante sobre o tema, admitindo textualmente a aposentadoria compulsória por invalidez como uma hipótese de suspensão do contrato de trabalho.

Ademais, também de forma correta, o Tribunal adotou o princípio da primazia da cláusula contratual mais benéfica para os empregados. Vários são os princípios instrumentais do Direito do Trabalho, mas, por certo, nenhum princípio tem tanta força quanto o da primazia da cláusula (ou norma) mais favorável ao empregado.

O princípio da primazia da cláusula contratual mais benéfica decorre de outro princípio específico do Direito do Trabalho, que é o reconhecimento da desigualdade existente entre o empregador e o empregado. Enquanto aquele detém o capital (meios de produção), o empregado possui apenas a sua força de trabalho ou conteúdo intelectual.

Diante da cristalina disparidade de forças, o que interferirá na condução do contrato de trabalho por eles celebrado, se fez necessário o reconhecimento da hipossuficiência do empregado em relação ao empregador. Portanto, a partir do momento em que o banco recorrente disponibiliza aos seus empregados uma assistência médica e odontológica, inclusive à empregada recorrida, não pode subtrair tal direito da trabalhadora em razão da aposentadoria por invalidez que, conforme já destacado, não tem o condão de rescindir o contrato de trabalho existente. A aposentadoria provisória apenas suspendeu o contato de trabalho da recorrida ${ }^{(4)}$.

(4) Apenas a título de uniformização de conceitos, a aposentadoria por invalidez também é chamada de aposentadoria provisória ou temporária. 
Vale destacar que, segundo a assertiva supra, caso novas vantagens fossem concedidas aos empregados do banco recorrente, tais benefícios teriam que ser estendidos à empregada recorrida, mesmo estando a trabaIhadora aposentada por invalidez.

O acórdão sob análise enfrenta ainda uma questão já consolidada na jurisprudência do Tribunal Superior do Trabalho e citada acima. Sustentou o banco recorrente que a aposentadoria por invalidez teria um tempo de validade; qual seja, cinco anos. Segundo este entendimento, após tal lapso temporal, a aposentadoria provisória seria convertida em aposentadoria definitiva e, com isso, estaria rescindido o contrato de trabalho, não havendo possibilidade de retorno às atividades laborais mesmo que a limitação física ou psicológica seja superada.

A investida do banco recorrente é cristalina, pois, se a realidade por ele desenhada fosse verídica, não teria incidência a regra do art. 468 da Consolidação das Leis do Trabalho no debate ora analisado, não sendo assegurada a manutenção do plano de saúde e odontológico da recorrida, pois o contrato de trabalho dela não estaria suspenso, mas sim rescindido.

Ocorre que o entendimento pretoriano dominante acerca do tema não comporta limitação temporal para a manutenção da aposentadoria por invalidez. Na verdade, a lógica imposta pelo intérprete tem sido a manutenção do trabalho. Assim, caso a limitação que impõe a suspensão do contrato de trabalho seja superada, a retomada da prestação do serviço é efetivada e a aposentadoria provisória revertida. Portanto, sob a ótica do Direito do Trabalho a recorrida continua sendo empregada do banco recorrente, tendo todos os direitos decorrentes do seu contrato de trabalho assegurados, com exceção do recebimento de salário uma vez que não existe a prestação de serviço.

Pelo Direito Previdenciário, a empregada recorrida consagra a qualidade de aposentada; no entanto, sua aposentadoria é provisória, podendo ser revista assim que suas limitações forem superadas.

E pela ótica do Direito Sanitário, como fica? Aqui se faz necessária a interação de princípios constitucionais para que o dilema seja solucionado.

A Constituição Federal em seu art. 1ำ apresenta os fundamentos da República Federativa do Brasil, dentre os quais está a proteção da dignidade da pessoa humana. Está garantido pelo Texto Constitucional o direito à vida e dentro deste contexto, à vida digna.

Assim, todas as iniciativas que retiram do indivíduo as condições mínimas para uma vida com qualidade, hombridade, respeito e dignidade colidem com a Constituição Federal e não podem receber a chancela do Ordenamento Jurídico.

Considerando que o motivo da aposentadoria da trabalhadora, no caso sob análise, foi a invalidez, é razoável concluir que ela necessitará de cuida- 
dos médicos diferenciados ao longo da sua vida, no mínimo, para tratar da enfermidade que ensejou a interrupção de sua atividade laborativa.

Diante dessa realidade a subtração do direito à manutenção do plano de saúde por parte do empregador consistiria em violação do princípio da proteção da dignidade da pessoa humana, pois, colocaria a empregada recorrida em uma situação de precariedade extrema.

A trabalhadora não conseguiria ingressar em um novo contrato de saúde com outra operadora de plano de saúde sem ter que observar os prazos de carência limitadores da prestação de atendimento e cobertura (com exceção dos casos de urgência e emergência onde o prazo de carência é reduzido). Além disso, a empregada recorrida ainda teria que enfrentar a discussão quanto à possibilidade ou não de cobertura do tratamento da sua doença por parte da operadora de saúde, tendo em vista a alegação de doença preexistente.

Assim, a interrupção da assistência de saúde não só coloca em risco o tratamento da empregada, mas também compromete (pelo menos em tese) a continuidade e a qualidade das intervenções médicas que vinham sendo ministradas.

A questão é tão séria que a própria Lei Federal n. 9.656/98 garante ao empregado dispensado a manutenção do plano de saúde custeado pela empresa aos seus empregados, desde que arque com a integralidade do pagamento da mensalidade. Com isso, não há que se falar em novo prazo de carência ou em restrições de coberturas por doenças preexistentes.

Não seria razoável que no caso da aposentadoria por invalidez não fosse assegurada ao aposentado a manutenção do seu plano de saúde nas mesmas condições que tinha quando empregado ativo. A restrição superveniente derivada da aposentadoria prematura violaria a dignidade do empregado aposentado.

O debate em tela atrai um outro princípio constitucional agasalhado pelo Direito Sanitário e essencial para a compreensão da decisão ora analisada. Trata-se do princípio do mínimo existencial.

O princípio do mínimo existencial é aquele que assegura a obtenção das necessidades básicas para a sobrevivência do indivíduo, tais como alimentação, saúde, educação, emprego e lazer. Nota-se claramente estreita relação entre o princípio do mínimo existencial e o princípio da proteção da dignidade da pessoa humana. Na verdade, a preservação do princípio da proteção da dignidade da pessoa humana é viabilizada pelo princípio do mínimo existencial.

Outro princípio também em voga atualmente e harmonizado com o princípio de proteção da dignidade da pessoa humana é o princípio da solidariedade. Tal princípio consiste na colaboração mútua para atender a uma finalidade coletiva.

Dentro deste contexto, a saúde deve ser compreendida como um direito fundamental apresentado pelo Texto Constitucional atual com uma conotação universal, cabendo ao Estado o seu fornecimento, suplementado pela iniciativa privada. 
O Poder Judiciário no caso sob análise, mediante o provimento jurisdicional conferido, fez mais do que simplesmente aplicar as normas de regência estabelecidas pela legislação trabalhista. O Poder Judiciário acabou por dar efetividade aos princípios constitucionais citados acima, principalmente ao princípio da proteção da dignidade da pessoa humana, ao assegurar à empregada recorrida a manutenção do plano de saúde custeado pela empresa empregadora recorrente.

Assim, trata-se de duas decisões judiciais (primeira e segunda instâncias) que harmonizam regras e princípios de diferentes ramos do Direito, dando uma solução humana e tecnicamente sustentável em face do ordenamento jurídico existente para uma situação que colocava em risco a dignidade da empregada recorrida. O Direito Sanitário empresta seus fundamentos para a concretização da prestação jurisdicional afastando o risco à saúde da empregada recorrida que poderia ter ficado sem o custeio da assistência médica disponibilizada pela sua empregadora.

Conforme destacado no início dessa análise, o Direito Sanitário ainda é um ramo do Direito em construção apesar de cuidar de demandas antigas. Sua aplicação pelos operadores do Direito ainda é inconsciente, pois, para muitos, o Direito Sanitário não possui a autonomia necessária para caracterizá-lo como um ramo próprio do Direito.

De qualquer sorte, é fundamental a consolidação dos princípios e fundamentos do Direito Sanitário para que ele se consolide e encontre o seu espaço dentro da divisão do Direito, sendo que decisões como as que foram aqui estudadas contribuem para isso.

\section{REFERÊNCIAS BIBLIOGRÁFICAS}

CASSAR, Vólia Bomfim. Direito do trabalho. Rio de Janeiro: Impetus, 2007. MORAES, Alexandre. Direito constitucional. São Paulo: Atlas, 2005.

SILVA, José Afonso da. Curso de direito constitucional positivo. São Paulo: Malheiros Ed., 2006.

\section{LEGISLAÇÃO:}

Consolidação das Leis do Trabalho - CLT.

Constituição da República Federativa do Brasil - CRFB.

Lei Federal n. 8.212/91.

Lei Federal n. 8.213/91.

Lei Federal n. 9.656/98. 